\title{
Natural aggregate totally replacement by mechanically treated concrete waste
}

\author{
Jozef Junak, Nadezda Stevulova \\ Technical University of Kosice \\ Civil Engineering Faculty, Institute of Environmental Engineering \\ e-mail: jozef.junak@tuke.sk, nadezda.stevulova@tuke.sk
}

\begin{abstract}
This paper presents the results obtained from the research focused on the utilization of crushed concrete waste aggregates as a partial or full replacement of $4 / 8$ and $8 / 16 \mathrm{~mm}$ natural aggregates fraction in concrete strength class C 16/20. Main concrete characteristics such as workability, density and compressive strength were studied. Compressive strength testing intervals for samples with recycled concrete aggregates were 2, 7, 14 and 28 days. The amount of water in the mixtures was indicative. For mixture resulting consistency required slump grade S3 was followed. Average density of all samples is in the range of $2250 \mathrm{~kg} / \mathrm{m}^{3}$ to $2350 \mathrm{~kg} / \mathrm{m}^{3}$. The highest compressive strength after 28 days of curing, $34.68 \mathrm{MPa}$, reached sample, which contained $100 \%$ of recycled material in $4 / 8 \mathrm{~mm}$ fraction and $60 \%$ of recycled aggregates in $8 / 16 \mathrm{~mm}$ fraction. This achieved value was only slightly different from the compressive strength $34.41 \mathrm{MPa}$ of the reference sample.
\end{abstract}

Key words: recycled concrete aggregate, workability, compressive strength

\section{Introduction}

The Integrated waste management is a frame of reference for designing and implementing new waste management systems and for analysing and optimising existing systems. Integrated waste management is based on the concept that all aspects of a waste management system (technical and non-technical) should be analysed together, since they are in fact interrelated and developments in one area frequently affect practices or activities in another area [1].

The waste hierarchy generally lays down a priority order of what constitutes the best overall environmental option in waste legislation and policy, while departing from such hierarchy may be necessary for specific waste streams when justified for reasons of, inter alia, technical feasibility, economic viability and environmental protection [2].

Reducing waste at source not only minimises the impact of waste treatment and disposal, it also enhances the efficient use of raw materials. However, despite the increasing emphasis on waste prevention, wastes have increased. Landfill and incineration, instead of recycling, are still the predominant practices in waste management, although differences exist between 
countries. Waste often still escapes control or avoids strict regulations through transfrontier movement across European countries and from Europe to developing countries [3].

In the world is increasing demand and interest in aggregates from non-traditional sources such as from industrial by-products and recycled construction and demolition wastes. The American Concrete Institute focuses on the removal and reuse of hardened concrete whereas the Department of the Environment and Water Resources in Australia and the Commonwealth Scientific and Industrial research Organisation has developed a guide on the use of recycled concrete and masonry materials. The Waste \& Resources Action Programme in the UK classified aggregates from primary, recycled and secondary material resources. Recycled aggregates encompass industrial by-products and reused construction products, all of which were once considered wastes and dumped in landfill. The recently introduced European Standards for aggregates do not discriminate between different sources, and are for 'aggregates from natural, recycled and manufactured materials' [4].

Classification of aggregates [5]:

1. Natural aggregate: construction aggregates produced from natural sources such as gravel and sand, and extractive products such as crushed rock,

2. Manufactured aggregate: aggregates manufactured from selected naturally occurring materials, by-products of industrial processes or a combination of these,

3. Recycled aggregate: aggregates derived from the processing of materials previously used in a product and/or in construction,

4. Reused by-product: aggregates produced from by-products of industrial processes.

Recycled concrete aggregate is generally produced by two-stage crushing of demolished concrete, and screening and removal of contaminants such as reinforcement, paper, wood, plastics and gypsum. Concrete made with such recycled concrete aggregate is called recycled aggregate concrete. When demolished concrete is crushed, a certain amount of mortar and cement paste from the original concrete remains attached to stone particles in recycled aggregate. This attached mortar is the main reason for the lower quality of recycled concrete aggregate compared to natural aggregate. Technology of recycled aggregate concrete production is different from the production procedure for concrete with natural aggregate. Because of the attached mortar, recycled aggregate has significantly higher water absorption than natural aggregate. Therefore, to obtain the desired workability of recycled aggregate concrete it is necessary to add a certain amount of water to saturate recycled aggregate before or during mixing, if no water-reducing admixture is applied. One option is to first saturate recycled aggregate to the condition - water saturated surface dry, and the other is to use dried recycled aggregate and to add the additional water quantity during mixing. The additional water quantity is calculated on the basis of recycled aggregate water absorption in prescribed time [6].

Many studies have shown that natural aggregates can be successfully replaced by slag and recycled concrete aggregate [7\&8], by crushed glass [9], but by bottom sediment also [10].

The very important descriptive characteristic of fresh concrete is workability. Workability of concrete is a term which consists of the following four partial properties of concrete namely, mixability, transportability, mouldability and compatibility. In general terms, workability represents the amount of work which is to be done to compact the compact the concrete in a given mould. The desired workability for a particular mix depends upon the type of compaction adopted and the complicated nature of reinforcement used in reinforced concrete. Workable concrete is the one which exhibits very little internal friction between particle and 
particle or which overcomes the frictional resistance offered by the formwork surface or reinforcement contained in the concrete with just the amount of compacting efforts forthcoming. To determine the suitability of the composition of the concrete mixture for transport, shaping and compacting, or the values of workability of fresh concrete the Slump test is used. For different works different slump values have been recommended [11].

The density of concrete is a measure of its unit weight. The density of normal concrete is $2400 \mathrm{~kg} / \mathrm{m}^{3}$ and the density of lightweight concrete is $1750 \mathrm{~kg} / \mathrm{m}^{3}$. The unit weight of concrete (density) varies depending on the amount and density of the aggregate, the amount of entrained air (and entrapped air), and the water and cement content [12].

Compressive strength is typically the most important mechanical property of concrete, because it correlates strongly with other properties such as tensile strength and many durability properties. Tensile strength measures the force required to pull something such as rope, wire, or a structural beam to the point where it breaks. The tensile strength of a material is the maximum amount of tensile stress that it can take before failure, for example breaking. For some applications, for instance precast residential basement wall panels, fibres may be added to the concrete mix for a number of reasons, but an increase in strength is not one of them. Strength is significant only insofar as the addition of fibres should not reduce it below the value specified by the producer [13].

The aim of this work is to experimentally verify the suitability of the substitution of fractions $4 / 8 \mathrm{~mm}$ and $8 / 16 \mathrm{~mm}$ natural aggregate by alternative raw-waste material. For this purpose, we chose the mechanically treated concrete waste. In verifying the replacement of selected fractions exact recipe for the concrete was followed. Main concrete characteristics such as workability, density and compressive strength were studied.

\section{Material and methods}

In our experiment, Portland cement CEM II 32.2, aggregate prepared from crushed and washed concrete waste and natural aggregates were used as raw materials.

Washed recycled concrete aggregate was created as a crushed and sorted waste from building and roads demolition. This material was obtained from recycling plant Rail and Transport Buildings, Ltd. Kosice, Slovakia. This secondary raw material, fraction $4 / 8\left(2413 \mathrm{~kg} / \mathrm{m}^{3}\right)$ and $8 / 16 \mathrm{~mm}\left(2529 \mathrm{~kg} / \mathrm{m}^{3}\right)$, was wash and used as natural aggregate replacement in concrete mixtures.

Three different fractions of mined natural aggregate $(0 / 4 \mathrm{~mm}, 4 / 8 \mathrm{~mm}$ and 8/16 $\mathrm{mm})$ from company VSH, (Slovakia, Geca) was used for concrete samples preparing. Natural aggregate was evaluated according to the standard STN EN 12620 Aggregates for concrete.

To manufacture of concrete samples Portland slag cement CEM II/B-S $32.5 \mathrm{R}$ from cement factory PCLA a.s. Ladce, Slovakia was used, according to the Slovakian standard STN EN 197-1 Cement. Part 1: Composition, specifications and conformity criteria for common cements.

As the mixing and caring water in the preparation of concrete samples were used drinking water from laboratory, which meets the requirements of standard STN EN 1008.

Table 1 shows proposal composition of $1 \mathrm{~m}^{3}$ of concrete for strength class C 16/20. 
Table 1: Composition of $1 \mathrm{~m}^{3}$ of concrete class C $16 / 20$

\begin{tabular}{|c|c|}
\hline Composition & C 16/20 XC1, (SK) - Cl 0,4 - D max 16 \\
\hline CEM II/ B-S 32.5 R [kg] & 300 \\
Water [1] & 165 \\
0/4 mm [kg] & 950 \\
$4 / 8 \mathrm{~mm}[\mathrm{~kg}]$ & 220 \\
8/16 mm [kg] & 700 \\
Plasticizer [1] & 2.15 \\
\hline
\end{tabular}

As an additive to concrete samples plasticizer Stacheplast was used. It is a plasticizer based on lignin, which specifically regulates the hardening of concrete samples with a strong plasticizing effect. The amount of water in the mixture was indicative. For mixture resulting consistency required slump grade S3 was followed.

Ten different mixtures based on recycled concrete aggregate (called R1-R10) at solid/liquid ratio of 0.55-0.6 (important was achieved slump grade S3), including admixture Stacheplast was performed in our study. Sample R1 was reference sample prepared only with natural aggregate. In the other mixtures (R2-R10) natural aggregate fractions, 4/8 and 8/16 mm were replaced by washed recycled concrete aggregate. The replacement variation in the experimental mixtures was in range 0 to $100 \%$, as it is shown in Table 2.

Table 2: Percentage replacement of natural aggregates by washed recycled concrete aggregates in the mixtures

\begin{tabular}{|c|c|c|}
\hline \multirow{2}{*}{ Sample } & \multicolumn{2}{|c|}{ Recycled concrete aggregates } \\
\cline { 2 - 3 } & $\begin{array}{c}4 / 8 \mathrm{~mm} \\
{[\%]}\end{array}$ & $\begin{array}{c}8 / 16 \mathrm{~mm} \\
{[\%]}\end{array}$ \\
\hline R1 & 0 & 0 \\
R2 & 100 & 20 \\
R3 & 100 & 40 \\
R4 & 100 & 60 \\
R5 & 100 & 80 \\
R6 & 100 & 100 \\
R7 & 20 & 100 \\
R8 & 40 & 100 \\
R9 & 60 & 100 \\
R10 & 80 & 100 \\
\hline
\end{tabular}

Experimental mixtures were processed in the laboratory mixer with a horizontal rotary drum with a capacity of $150 \mathrm{l}$. Compounding process was chosen as follows: after dry mixing of aggregate $(8 / 16 \mathrm{~mm}, 4 / 8 \mathrm{~mm}, 0 / 4 \mathrm{~mm})$ alone cement was added, followed by further mixing. Stirring mixture was added water, and as the last ingredient was added plasticizer Stacheplast. This mixture was stirred for about 90s. After a careful mixing of the all components concrete mixture were placed into cleaned plastic forms. Thus prepared forms were then over $15 \mathrm{~s}$ compacted on a vibrating table. After filling, cubic forms were labelled and placed on a flat surface next 48 hours. After 48 hours, the cube bodies were removed from the forms and then 
placed in a water bath. In order to realize the experiment program 48 pieces of test cubes with dimensions of 150x150x150 mm were made. Hardening time of samples contained recycled concrete aggregates was 2, 7, 14 and 28 days. Compressive strength testing intervals for samples with recycled concrete aggregates is given in Table 3. For samples R1, R2, R6, R7 the strength after 2 days and 7days were observed in order to obtain the starting compressive strength. The actual test compressive strength of the samples was carried out on the hydraulic bench press ADR ELE 2000, UK.

Table 3: Compressive strength testing intervals

\begin{tabular}{|c|c|}
\hline Sample & Days \\
\hline R1 & $2,7,14,28$ \\
R2 & $2,7,14,28$ \\
R3 & 14,28 \\
R4 & 14,28 \\
R5 & 14,28 \\
R6 & $2,7,14,28$ \\
R7 & $2,7,14,28$ \\
R8 & 14,28 \\
R9 & 14,28 \\
R10 & 14,28 \\
\hline
\end{tabular}

The most important descriptive characteristic of fresh concrete is workability. For the purpose of this experiment Slump test was selected and performed, according to the Slovakian standard STN EN 12350-2. In the test, fresh concrete was compacted in the form of a hollow truncated cone. The aim of the test is to determine the suitability of the composition of the concrete mixture for transport, shaping and compacting, or the values of workability of fresh concrete. The measured values of slump test of fresh concrete by this method are given in Table 4. As it is evident, in the investigated samples slump grade S3 was achieved, what was the intention.

Table 4: The measured values of fresh concrete slump test

\begin{tabular}{|c|c|c|}
\hline Sample & $\begin{array}{c}\text { Slump } \\
{[\mathrm{mm}]}\end{array}$ & $\begin{array}{c}\text { Slump } \\
\text { grade }\end{array}$ \\
\hline R1 & 165 & $\mathrm{~S} 3$ \\
R2 & 170 & $\mathrm{~S} 3$ \\
R3 & 155 & $\mathrm{~S} 3$ \\
R4 & 150 & $\mathrm{~S} 3$ \\
R5 & 160 & $\mathrm{~S} 3$ \\
R6 & 160 & $\mathrm{~S} 3$ \\
R7 & 155 & $\mathrm{~S} 3$ \\
R8 & 160 & $\mathrm{~S} 3$ \\
R9 & 160 & S3 \\
R10 & 165 & S3 \\
\hline
\end{tabular}




\section{Results and discussion}

Table 5 shows the average density values of three samples obtained from each mixture after 28 days of hardening. It is evident that the density of the reference sample is almost identical to the density of the sample called R6, in which natural aggregates by crushed concrete waste had been completely replaced. The lowest density reached sample R10, containing $80 \%$ of recycled material in $4 / 8 \mathrm{~mm}$ fraction and $100 \%$ of recycled aggregates in $8 / 16 \mathrm{~mm}$ fraction. Average density of all samples is in the range from $2250 \mathrm{~kg} / \mathrm{m}^{3}$ to $2350 \mathrm{~kg} / \mathrm{m}^{3}$.

Table 5: Average values of density after 28 days of curing

\begin{tabular}{|c|c|c|}
\hline Sample & $\begin{array}{c}\text { Average weight } \\
{[\mathrm{kg}]}\end{array}$ & $\begin{array}{c}\text { Average density } \\
{\left[\mathrm{kg} / \mathrm{m}^{3}\right]}\end{array}$ \\
\hline R1 & 7.736 & 2340 \\
R2 & 7.732 & 2320 \\
R3 & 7.659 & 2310 \\
R4 & 7.608 & 2260 \\
R5 & 7.660 & 2260 \\
R6 & 7.847 & 2350 \\
R7 & 7.705 & 2320 \\
R8 & 7.814 & 2330 \\
R9 & 7.627 & 2290 \\
R10 & 7.600 & 2250 \\
\hline
\end{tabular}

Table 6 shows compressive strength of samples prepared with recycled concrete aggregates after curing.

Table 6: Compressive strength samples prepared with recycled concrete aggregate after 2, 7, 14 and 28 days of curing

\begin{tabular}{|c|c|c|c|c|}
\hline \multirow{2}{*}{ Sample } & \multicolumn{4}{|c|}{ Compressive strength [MPa] } \\
\cline { 2 - 5 } & 2 days & 7 days & 14 days & 28 days \\
\hline R1 & 5.77 & 20.54 & 26.21 & 34.41 \\
R2 & 9.2 & 20.98 & 27.99 & 33.83 \\
R3 & - & - & 23.49 & 29.79 \\
R4 & - & - & 27.85 & 34.68 \\
R5 & - & - & 28.28 & 33.47 \\
R6 & 6.38 & 19.01 & 24.61 & 28.65 \\
R7 & 7.32 & 17.37 & 23.19 & 28.38 \\
R8 & - & - & 25.33 & 27.42 \\
R9 & - & - & 21.33 & 27.59 \\
R10 & - & - & 25.71 & 32.33 \\
\hline
\end{tabular}

Only in the four concrete samples (R1, R2, R6 and R7) start-up compressive strength after 2 and 7 days of hardening was observed.

From the analysis of obtained results follows, that samples R1 and R2 after 7 days of 
hardening meet the minimum strength of $20 \mathrm{MPa}$ according to standard STN EN 206-1, but samples R6 and R7 fulfill this requirement after 28 days. From Table 6 it is evident that all samples meet the requirement of a standard (compressive strength $20 \mathrm{MPa}$ ), already after 14 days of hardening. The highest compressive strength after 28 days of hardening reached sample R4 (34.68 MPa; $100 \%$ recycled fraction $4 / 8 \mathrm{~mm}$, and $60 \%$ recycled fraction $8 / 16$ $\mathrm{mm}$ ), but this is only slightly different from the strength of the reference sample R1 (34.41 $\mathrm{MPa}$ ). The lowest strength reached sample R8 (40\% recycled fraction 4/8 mm and 100\% recycled fraction $8 / 16 \mathrm{~mm}$ ). The different compressive strength were achieved as a result of varying percentages substitute for natural aggregates by recycling concrete aggregates.

\section{Conclusion}

This paper presents the results obtained from the research focused on the utilization of crushed waste concrete aggregates as a partial or full replacement of 4/8 and 8/16 mm natural aggregates fraction in concrete strength class C 16/20. Main concrete characteristics such as workability, density and compressive strength were studied.

The most important descriptive characteristic of fresh concrete is workability. For the purpose of this experiment Slump test was selected and performed. The amount of water in the mixture was indicative. For mixture resulting consistency required slump grade S3 was followed.

The density of concrete is a measure of its unit weight and it varies depending on the amount and density of the aggregate, the amount of entrained air and the water and cement content. Average density of all samples is in the range of $2250 \mathrm{~kg} / \mathrm{m}^{3}$ to $2350 \mathrm{~kg} / \mathrm{m}^{3}$. The density of the reference sample is almost identical to the density of the sample, which had been completely replaced by recycled concrete aggregates. The lowest density reached sample R10, containing $80 \%$ of recycled material in $4 / 8 \mathrm{~mm}$ fraction and $100 \%$ of recycled aggregates in $8 / 16 \mathrm{~mm}$ fraction.

Compressive strength testing intervals for samples with recycled concrete aggregates were 2 , 7, 14 and 28 days. The highest compressive strength after 28 days of hardening, $34.68 \mathrm{MPa}$, reached sample, which contained $100 \%$ of recycled material in $4 / 8 \mathrm{~mm}$ fraction and $60 \%$ of recycled aggregates in $8 / 16 \mathrm{~mm}$ fraction. This achieved value was only slightly different from the compressive strength $34.41 \mathrm{MPa}$ of the reference sample. The lowest compressive strength reached sample, which was prepared with $40 \%$ of recycled fraction $4 / 8 \mathrm{~mm}$ and $100 \%$ of recycled fraction $8 / 16 \mathrm{~mm}$.

Results show that it should be possible to replace the two selected fractions of natural aggregates by recycled concrete aggregates to prepare lower strength classes of recycled aggregate concrete.

\section{Acknowledgements}

This research has been carried out within the Grant No. 1/0767/13 of the Slovak Grant Agency for Science. 


\section{References}

[1] United Nations environment programme. (2005). Solid Waste Management. Concord: CalRecovery. $\quad$ 14.5.2015, http://www.unep.org/ietc/Portals/136/SWM-Vol1-Part1Chapters1to3.pdf.

[2] European Parliament. (2008). Directive 2008/98/EC of the European Parliament and of the Council of 19 November 2008 on waste and repealing certain Directives. Strasbourg: European Parliament.

[3] European Environment Agency. (14.4.2011). Waste Production and Management. 14.5.2015, http://www.eea.europa.eu/publications/92-826-5409-5/page036new.html.

[4] Cement Concrete and Aggregates Australia. (2008). Use of Recycled Aggregates in Construction. Sydney: Cement Concrete and Aggregates Australia. 14.5.2015, http://www.ccaa.com.au/imis_prod/documents/Library\%20Documents/CCAA\%20Reports/Rec ycledAggregates.pdf.

[5] Alexander M. \& Mindess S. (2010). Aggregates in Concrete. New York: Taylor \& Francis Group.

[6] Malesev M., Radonjanin V. \& Marinkovic S. (2010). Recycled Concrete as Aggregate for Structural Concrete Production. Sustainability. Vol. 2(5), 1204-1225.

[7] Junak J. \& Stevulova N. (2013). Natural Aggregate Replacement by Recycled Materials in Concrete Production. Visnik Nacional'nogo universitetu L'vivska politechnika: teorija i praktika budivnictva. No. 756, 63-68.

[8] Vaclavik V., Dirner V., Dvorsky T. \& Daxner J. (2012). Use of blast furnace slag. Metalurgija. Vol. 51, 461-464.

[9] Junak J. \& Sicakova A. (2014). Glass Waste as an Alternative to Natural Aggregate. In International Multidisciplinary scientific Geoconference, 17.-26.6.2014, Albena, Bulgaria (pp. 321-326). Sofia: STEF92 Technology.

[10] Junakova N. \& Balintova M. (2014). The Study of Bottom Sediment Characteristics as a Material for Beneficial Reuse. Chemical Engineering. Vol. 39, 637-642.

[11] Nie M. (2014). Workability of Concrete. 14.5.2015, http://elearning.vtu.ac.in/16/ENotes/ConcreteTechnology/unit3-NS.pdf

[12] Raheem A.A., Soyingbe A.A. \& Emenike A.J. (2013). Effect of Curing Methods on Density and Compressive Strength of Concrete. International Journal of Applied science and Technology. Vol. 3(4), 55-64.

[13] Kausay T. \& Simon T.K. (2007). Acceptance of Concrete Compressive Strength. Concrete Structures. Vol. 8, 54-63. 